CLINICAL STUDY

\title{
GH response to GHRH plus arginine is impaired in lipoatrophic women with human immunodeficiency virus compared with controls
}

\author{
Lucia Zirilli ${ }^{1}$, Gabriella Orlando ${ }^{2}$, Federica Carli ${ }^{2}$, Bruno Madeo $^{1}$, Stefania Cocchi ${ }^{2}$, Chiara Diazzi ${ }^{1}$, Cesare Carani ${ }^{1}$, \\ Giovanni Guaraldi ${ }^{2}$ and Vincenzo Rochira ${ }^{1}$ \\ ${ }^{1}$ Chair of Endocrinology, Integrated Department of Medicine, Endocrinology, Metabolism, and Geriatrics and ${ }^{2}$ Clinic of Infectous Diseases, Department \\ of Medicine and Medical Specialties, University of Modena and Reggio Emilia, Via Giardini 1355, 41100 Modena, Italy
}

(Correspondence should be addressed to V Rochira; Email: rochira.vincenzo@unimore.it)

\begin{abstract}
Objective: GH secretion is impaired in lipodystrophic human immunodeficiency virus (HIV) patients and inversely related to lipodystrophy-related fat redistribution in men. Less is known about the underlying mechanisms involved in reduced GH secretion in HIV-infected women.

Design: A case-control, cross-sectional study comparing GH/IGF1 status, body composition, and metabolic parameters in 92 nonobese women with HIV-related lipodystrophy and 63 healthy controls matched for age, ethnicity, sex, and body mass index (BMI).

Methods: GH, IGF1, IGF binding protein 3 (IGFBP3), GH after GHRH plus arginine (GHRH+Arg), several metabolic variables, and body composition were evaluated.

Results: GH response to GHRH + Arg was lower in HIV-infected females than in controls. Using a cutoff of peak $\mathrm{GH} \leq 7.5 \mu \mathrm{g} / \mathrm{l}, 20.6 \%$ of HIV-infected females demonstrated reduced peak GH response after $\mathrm{GHRH}+$ Arg. In contrast, none of the control subjects demonstrated a peak GH response $\leq 7.5 \mu \mathrm{g} / \mathrm{l}$. Bone mineral density (BMD), quality of life, IGF1, and IGFBP3 were lowest in the HIV-infected females with a $\mathrm{GH}$ peak $\leq 7.5 \mu \mathrm{g} / \mathrm{l}$. BMI was the main predictive factor of $\mathrm{GH}$ peak in stepwise multiregression analysis followed by age, with a less significant effect of visceral fat in the HIV-infected females. Conclusions: This study establishes that i) GH response to GHRH+Arg is lower in lipoatrophic HIVinfected women than in healthy matched controls, ii) BMI more than visceral adipose tissue or trunk fat influences $\mathrm{GH}$ peak in this population, and iii) HIV-infected women with a GH peak below or equal to $7.5 \mu \mathrm{g} / \mathrm{l}$ demonstrate reduced IGF1, IGFBP3, BMD, and quality of life.
\end{abstract}

European Journal of Endocrinology 166 415-424

\section{Introduction}

Human immunodeficiency virus 1 (HIV-1)-infected patients undergoing treatment with highly active antiretroviral therapy (HAART) demonstrate a number of endocrine and metabolic complications (1, 2). Reduced GH secretion occurs in about one-third of HIV-infected male patients $(3,4)$ with HIV/HAARTassociated lipodystrophy (HAL) (5). GH response to GHRH plus arginine $(\mathrm{GHRH}+\mathrm{Arg})$ is impaired in HIVinfected men compared with age- and body mass index (BMI)-matched male HIV-uninfected controls $(6,7,8)$. In HIV-infected men, however, reduced GH secretion occurs more frequently in patients with lipodystrophy $(6,9)$, while no study compared lipodystrophic with nonlipodystrophic women. Accordingly, the GH/IGF1 axis has been less well studied in HIV-infected women $(3,7)$ compared with men $(6,7,8,9)$. Among females, GH secretion did not differ between HIV and control subjects $(3,7)$, while no data are available in relatively lipoatrophic HIV-infected women. Reduced GH secretion is related to fat redistribution $(3,4,6,7,8,9)$ and elevated free fatty acids (FFA) in men $(3,4,9)$, but this association seems to be less pronounced or absent in women (3, 7). Among HIV-infected $(3,7)$ and HIV-uninfected subjects (10), gender differences in GH secretion and body composition effects are seen $(11,12)$.

The GHRH + Arg test has been used as a tool for diagnosing adult-onset GH deficiency (GHD) (13, 14, $15,16)$. GHRH + Arg, however, is less accurate in overweight and obese patients due to the inhibition of GH secretion exerted by adipose tissue, especially visceral fat $(10,17)$. To improve GHRH + Arg reliability and prevent misdiagnosis, more restrictive, BMI-based cutoffs are preferred in obese and overweight HIVuninfected subjects $(14,18)$. The increase in FFA, a phenomenon related to visceral obesity, may explain the blunted GH secretion in HIV-infected men (9). However, other mechanisms are possible $(9,19)$. HIV-infected 
patients demonstrate significant changes in body composition (5) and may thus demonstrate abnormalities in GH secretion. Moreover, consideration has been given to increasing GH in HIV patients to improve metabolic abnormalities, and recombinant human GH (r-hGH) as well as a GHRH-releasing analog, recently been approved by the FDA in this regard, have been considered $(6,7,20,21,22,23)$.

In this case-control, cross-sectional study, we compared the $\mathrm{GH}$ response to $\mathrm{GHRH}+\mathrm{Arg}$ in lipoatrophic, nonobese, HIV-infected women with HAL and healthy HIV-uninfected controls matched for sex, age, ethnicity, and BMI. In order to avoid the possible effect of obesity on GH secretion $(10,14,17,18)$, we chose to enroll nonobese HIV-infected females. The aim of the study was to investigate the prevalence of GHD in these HIV-infected females and explore the relationship among GH/IGF1 status, body composition, and metabolic parameters.

\section{Subjects and methods}

\section{Subjects}

We performed a case-control, cross-sectional study at the University of Modena and Reggio Emilia by prospectively enrolling 92 Caucasian female outpatients with HIV-related HAL and 63 healthy control women. The HIV-infected female patients were consecutively selected according to inclusion and exclusion criteria among female outpatients attending the Clinic of Infectious Diseases over a period from October 2005 to December 2010. Similarly, healthy control women were selected among asymptomatic women with documented normal thyroid hormones who referred to the Laboratory and Chair of Endocrinology of the University of Modena and Reggio Emilia from January 2006 to December 2010 for a screening program of thyroid function. The patients and the controls were matched for sex, ethnicity, age - between 18 and 57 years - and BMI with a difference minimization approach. In order to avoid obesity as a confounding factor for the study of $\mathrm{GH}$ secretion, we restricted the enrollment to nonobese HIV-infected and -uninfected females with a BMI $\leq 29.9 \mathrm{~kg} / \mathrm{m}^{2}$. With this criterion of enrollment, the HIV-infected patients demonstrated relative lipoatrophy in terms of changes in body composition (see Results section for details). Basal anthropometric and biochemical evaluations are summarized in Table 1.

Inclusion criteria The HIV-infected women had a physician-confirmed diagnosis of lipodystrophy according to the HIV Outpatients Study definition (24), with or without metabolic alterations; they had documented HIV infection for more than 5 years and were receiving HAART for least 6 months.
Exclusion criteria The exclusion criteria were: a BMI $\geq 30 \mathrm{~kg} / \mathrm{m}^{2}$; diabetes mellitus; signs, symptoms, or a medical history of pituitary disease; a previous conventional pituitary surgery or radiotherapy; hypogonadism; pregnancy; previous or current treatment with corticosteroids and/or exogenous estrogens; use of oral hypoglycemic drugs, insulin; and a history of r-hGH treatment within the 3 months preceding enrollment in the study.

\section{Methods}

All subjects underwent venous blood sampling at $0800 \mathrm{~h}$ after an overnight fast. All blood samples were stored at $-80{ }^{\circ} \mathrm{C}$ until assayed in the same laboratory. The population enrolled for the research protocol underwent biochemical and endocrinological evaluations including GHRH+Arg testing.

Assessment of GH secretion The GH-IGF1 system was studied under basal condition assaying serum GH, IGF1, and insulin growth factor binding protein 3 (IGFBP3) and under dynamic testing.

A standardized $\mathrm{GHRH}+\mathrm{Arg}$ test was performed (GHRH 1-29; GEREF, Serono; $1 \mu \mathrm{g} / \mathrm{kg}$ i.v. at $0 \mathrm{~min}$; arginine chlorhydrate, $0.5 \mathrm{~g} / \mathrm{kg}$ i.v. for $30 \mathrm{~min}$, from 0 to $+30 \mathrm{~min}$, up to a dose of $30 \mathrm{~g}$ ). Blood samples were obtained every $15 \mathrm{~min}$ from -15 to $+60 \mathrm{~min}$ and then every $30 \mathrm{~min}$ till $120 \mathrm{~min}$, as previously standardized $(15,18)$. GH peak response to GHRH + Arg test was evaluated in all the 155 subjects enrolled in the study according to different cutoff values $(6,7,15,16,18)$. The threshold of $\mathrm{GH}$ peak of $7.5 \mu \mathrm{g} / \mathrm{l}$ was used to separate normal from impaired responses to GHRH + Arg in both the HIV-infected patients and the healthy controls as it was previously used in studies on HIVinfected subjects $(6,7,8)$ and it is close to that of $8.0 \mu \mathrm{g} / \mathrm{l}$, which is commonly used for overweight subjects (18). The parameters used to evaluate the GH response to GHRH + Arg were the serum GH peak and the area under the curve (AUC).

Other hormonal and biochemical parameters Serum estradiol, glucose, insulin, and lipid profile (triglycerides, total cholesterol, LDL, and HDL) were measured in all subjects.

HIV infection-related parameters The HIV infection characteristics (i.e. duration of HIV infection, Centers for Disease Control and Prevention classification, antiretroviral class and single-drug exposure, and Nadir CD4 count) were obtained from medical records. The CD4 cell count and quantitative plasma HIV RNA viral load were assayed in the $92 \mathrm{HIV}$-infected patients.

Body composition and adipose tissue distribution Demographic characteristics (age, race, and sex) and anthropometric measurements were obtained during the medical examination and by means of dual-energy X-ray absorptiometry (DXA) for all the subjects enrolled, 


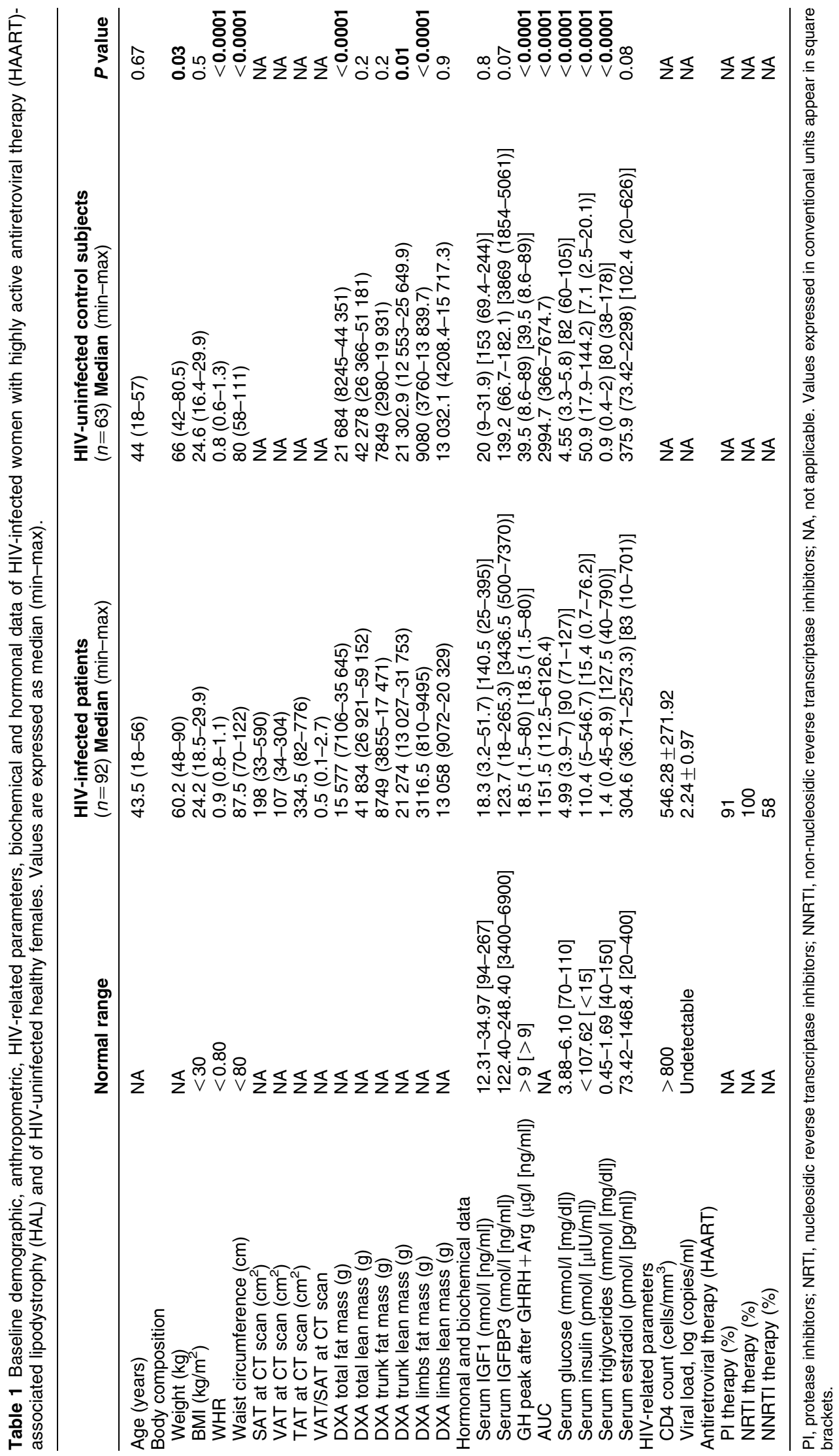


while an abdominal CT scan was performed only on the 92 HIV-infected patients. The healthy controls did not receive a CT scan for ethical reasons (see Ethics section).

We measured weight after a 5-h fast and height by stadiometer; we calculated waist and hip circumferences as the average of three measurements.

A whole body composition study (lean and fat mass) was performed by DXA (Hologic, Inc., Waltham, MA, USA) according to standardized procedures (25) and with precision of $3 \%$ for the measurement of fat mass and $1.5 \%$ for fat-free mass (26). The abdominal adipose tissue distribution was studied by CT scans at L4 level, with a single-slice abdominal scan as in standard protocols. Abdominal visceral adipose tissue (VAT) and abdominal subcutaneous adipose tissue (SAT) were determined (27), total abdominal adipose tissue (TAT) being the sum of VAT and SAT.

Assessment of quality of life In a subset of 70 HIVinfected patients and 49 control women, we evaluated quality of life by the two validated questionnaires for GHD in adults: the Questions on Life Satisfaction Hypopituitarism (QLS-H) and Adult GH Deficiency Assessment (AGHDA) (28). The scores were calculated according to standard instructions (28).

Laboratory analysis Serum IGF1 was measured by RIA (INCSTAR Corp., Stillwater, MN, USA), with linear reading up to $0.002 \mathrm{nmol} / \mathrm{l}$ and inter- and intra-assay coefficients of variation of 12 and $8 \%$ respectively. Serum IGFBP3 was measured by immunochemiluminescence (LIAISON Nichols Advantage, San Juan Capistrano, CA, USA), with inter- and intra-assay coefficients of variation of 4.8 and $5 \%$ respectively. Serum GH was measured using a fluoroimmunometric assay (LIAISON DIASORIN Autodelfia hGH kit, Stillwater, MN, USA) with a sensitivity of $0.02 \mu \mathrm{g} / \mathrm{l}$, linear reading up to $80 \mu \mathrm{g} / \mathrm{l}$, and inter- and intra-assay coefficients of variation of 5.5 and $4.9 \%$ respectively. Serum estradiol was assayed by RIA (Third-Generation DSL-39100; Diagnostic Systems Laboratories, Inc., Webster, TX, USA) with a sensitivity of $2.2 \mathrm{pmol} / \mathrm{l}$ $(0.6 \mathrm{pg} / \mathrm{ml})$, and the coefficients of variation were 4.1-9.9\% (inter-assay) and 3.4-3.9\% (intra-assay). Glucose, insulin, and lipid profile (triglycerides, total cholesterol, LDL, and HDL) were assayed using commercially available kits. The CD4 cell count was performed by flow cytometry (Becton Dickinson Immunocytochemistry Systems, San Jose, CA, USA). Quantitative plasma HIV RNA viral load was performed by ultrasensitive method (Amplicor HIV-1 Monitor Assay; Roche Molecular Systems), with the detection range between 50 and 75000 copies $/ \mathrm{ml}$.

\section{Statistical analysis}

The nonparametric Mann-Whitney $U$ test was used for comparisons because most of the variables were not normally distributed by the Kolmogorov-Smirnov test. The comparison among groups was performed using the nonparametric Kruskal-Wallis test (when more than two groups) followed by the Dunn's multiple comparison post hoc test when a significant difference was found in order to determine differences between individual groups. All the data are shown as median and minimum to maximum (min-max) in parenthesis.

The number of subjects with normal or impaired GH peak responses to GHRH + Arg according to different cutoffs is expressed as percentages.

We evaluated demographic, anthropometric, metabolic, and hormonal variables in order to identify possible predictive factors for $\mathrm{GH}$ response to $\mathrm{GHRH}+$ Arg in HIV-infected females. A stepwise, linear, multiple regression analysis was performed using serum $\mathrm{GH}$ peak and the AUC as dependent variables in two different analyses, and age, BMI, total lean body mass, trunk lean mass, trunk fat mass, insulin, triglycerides, and waist circumference as independent variables. A second, stepwise, linear, multiple regression analysis was performed only in HIV-infected individuals by using independent variables of body composition obtained by abdominal CT scan (VAT, SAT, and TAT) instead of those obtained by DXA, without modifying the dependent variables and all the other independent variables.

All multiple regression analyses were based on a single regression analysis for each predictor independent variable that allowed identifying candidate predictive variables. A univariate analysis was performed before multivariate analysis (Supplementary Tables 1 and 2, see section on supplementary data given at the end of this article). The independent variables with significance of $P$ value $<0.05$ were included in the regression model. Stepwise, linear, multiple regression analysis using a backward elimination method was applied to the data with $P<0.10$ as the criterion for a variable to be considered in the model. The percentage contribution of a given variable to the variance of both the GH peak and the AUC was determined by using the square of the Pearson correlation coefficient $\left(r^{2}\right)$.

Statistical analysis was performed using the 'Statistical Package for the Social Sciences' software for Windows (version 16.0; SPSS, Inc., Chicago, IL, USA) and Sigma Plot (version 11.00 for Windows; Systat Software, Inc., San Jose, CA, USA) for Kruskal-Wallis and the Dunn's tests. For all comparisons, $P$ values $<0.05$ were considered statistically significant.

\section{Ethics}

All subjects (both HIV-infected patients and HIVuninfected healthy females) gave written informed consent for participation in the study and for the publication of the data. The local Institutional Review Board (Comitato Etico di Modena) approved the study (N. 158/07). The 63 healthy controls did not receive 
a CT scan to avoid any radiation exposure. HIV-infected females underwent CT scanning of the abdomen to obtain information on the relationship between fat accumulation and $\mathrm{GH}$ secretion.

\section{Results}

Ninety-two nonobese HIV-infected lipodystrophic female patients were compared with 63 HIV-negative matched controls (Table 1).

Weight, total fat mass, trunk lean mass, and limb fat mass at DXA were significantly lower in the HIV-infected females than in uninfected females (Table 1), but BMI was similar. Waist circumference and WHR values were significantly higher in HIV-infected females than in controls $(P<0.0001)$. The percentage of total body fat mass was lower than in controls (27 vs 34\%). HIVinfected females did not show any statistically significant difference in other variables of body composition when compared with controls. Serum glucose, insulin, and triglycerides were significantly higher in the HIVinfected females than in controls $(P<0.0001$; Table 1$)$. $\mathrm{GH}$ peak and AUC were significantly lower in HIVinfected females than in controls $(P<0.0001)$, while the IGF1 and IGFBP3 levels did not significantly differ between the two groups (Table 1). Of the $92 \mathrm{HIV}$ infected women, ten $(10.9 \%)$ were postmenopausal; similarly, seven of the 63 HIV-uninfected women $(11.0 \%)$ were postmenopausal. Thus, the percentage of pre- and postmenopausal women did not differ between HIV-infected patients and controls. Of the postmenopausal women, four of ten HIV-infected women had a $\mathrm{GH}$ peak below $9 \mu \mathrm{g} / \mathrm{l}$, while none of the seven HIV-uninfected postmenopausal women had a $\mathrm{GH}$ peak below $9 \mu \mathrm{g} / \mathrm{l}$.

When different cutoffs for the GH peak after GHRH+ Arg were considered, the percentage of HIV-infected patients failing to reach a normal GH peak varied according to the cutoff used (Fig. 1). Using restrictive cutoffs such as 4.2 and $5 \mu \mathrm{g} / \mathrm{l}, 8.7 \%$ ( $n=8$ subjects) of the HIV-infected patients failed to reach a $\mathrm{GH}$ peak above both these thresholds (Fig. 1). Using the cutoffs of 7.5 and $8 \mu \mathrm{g} / \mathrm{l}, 20.6$ and $22.8 \%$, respectively $(n=19$ and 21 subjects respectively) of the HIV-infected patients failed to reach a $\mathrm{GH}$ peak above these thresholds (Fig. 1). Finally, using a cutoff of $9 \mu \mathrm{g} / \mathrm{l}$, commonly used in clinical practice for normal, healthy nonobese subjects, the percentage of HIV-infected patients with reduced $\mathrm{GH}$ response rose to $28.2 \%$ ( $n=26$ subjects; Fig. 1). Among the 63 controls, only one $(1.6 \%)$ failed to reach a $\mathrm{GH}$ peak above $9 \mu \mathrm{g} / \mathrm{l}$ (GH peak of $8.6 \mu \mathrm{g} / \mathrm{l}$; Fig. 1).

When the HIV-infected females were divided according to the cutoff of $7.5 \mu \mathrm{g} / \mathrm{l}$, also used previously in the context of HIV infection $(6,7,8)$, IGF1 and IGFBP3, lumbar, femoral, and total body bone mineral density (BMD) were significantly lower in the HIV-infected

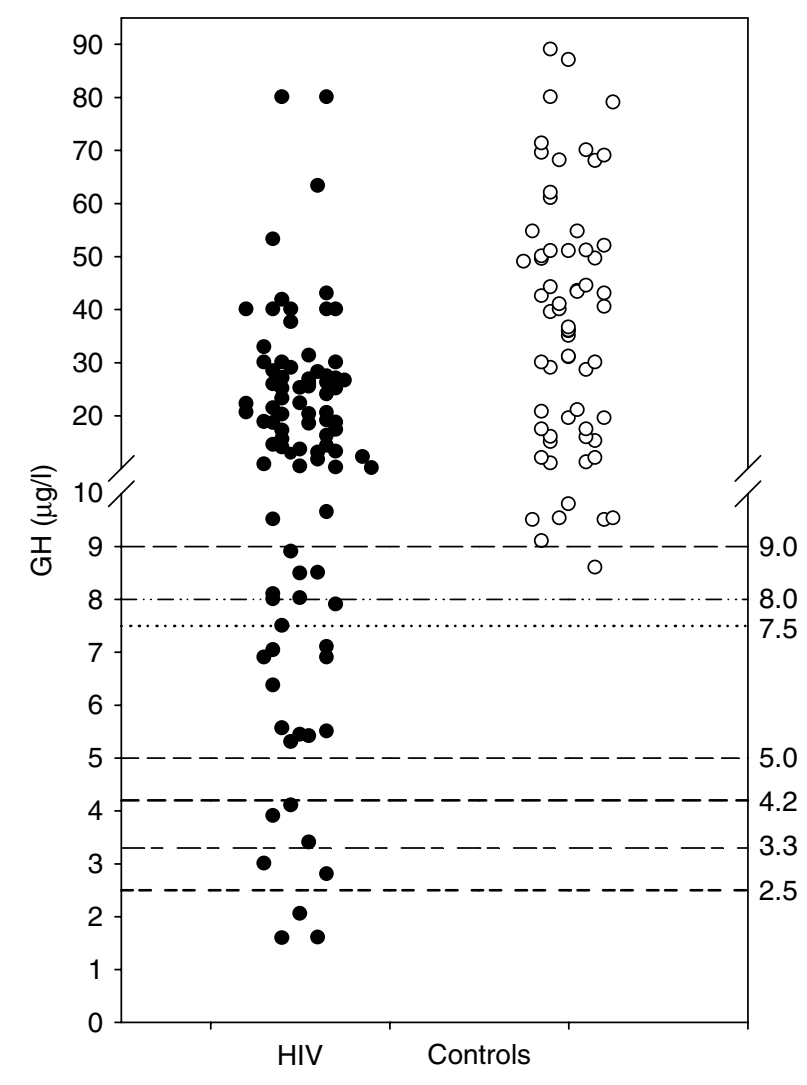

Figure 1 Comparison of GH peak responses between HIV-infected patients and HIV-uninfected healthy controls based on the different cutoffs considered.

women with a GH peak $\leq 7.5 \mu \mathrm{g} / \mathrm{l}$ than in HIV-infected females with a GH peak $>7.5 \mu \mathrm{g} / \mathrm{l} \quad(P<0.001$; Supplementary Table 3, see section on supplementary data given at the end of this article). Of interest, in a subset of participants, the quality-of-life scores were lower in the $15 \mathrm{HIV}$-infected women with a GH peak $\leq 7.5 \mu \mathrm{g} / \mathrm{l}$ than in $55 \mathrm{HIV}$-infected females with a $\mathrm{GH}$ peak $>7.5 \mu \mathrm{g} / \mathrm{l}(P<0.001$; Supplementary Table 3).

As far as body composition parameters at CT scan are concerned, SAT, VAT, and TAT did not differ significantly between the HIV-infected women with a GH peak $\leq 7.5 \mu \mathrm{g} / \mathrm{l}$ (SAT: median $184 \mathrm{~cm}^{2}$, VAT: median $142 \mathrm{~cm}^{2}$, and TAT: median $362 \mathrm{~cm}^{2}$ ) and the HIVinfected women with a $\mathrm{GH}$ peak $>7.5 \mu \mathrm{g} / \mathrm{l}$ (SAT: median $207 \mathrm{~cm}^{2}$, VAT: median $104 \mathrm{~cm}^{2}$, and TAT: median $325 \mathrm{~cm}^{2}$ ).

Estradiol in univariate analysis was not associated with GH peak and AUC in either HIV-infected women (Supplementary Table 1) or controls (Supplementary Table 2). BMI, age, total lean mass, trunk lean mass, trunk fat mass, waist circumference, VAT, and TAT were associated with both GH peak and AUC in HIV-infected women (Supplementary Table 1). BMI, age, trunk fat mass, insulin, triglycerides, and waist circumference were all associated with both $\mathrm{GH}$ peak and AUC in 
controls (Supplementary Table 2). When considering CT-scan parameters, GH peak $(r=0.318)$ and AUC $(r=0.319)$ were inversely related to VAT. Stepwise, linear, multiple regression analysis of the HIV-infected group, using the parameters of body fat measured by DXA as independent variables, indicated that BMI was the most significant predictive factor for $\mathrm{GH}$ peak after GHRH $+\operatorname{Arg}\left(r^{2}=0.11\right)$, followed by age and total lean mass when the $\mathrm{GH}$ peak was the dependent variable (Table 2), while BMI was the most significant predictive factor for AUC $\left(r^{2}=0.15\right)$, followed by age when AUC was the dependent variable (Table 2).

Stepwise, linear, multiple regression analysis of the HIV-infected group, using the parameters of body fat measured by abdominal CT scan (SAT, VAT, and TAT) instead of those obtained by DXA as independent variables, indicated that BMI was the most significant predicting factor of both $\mathrm{GH}$ peak after $\mathrm{GHRH}+\mathrm{Arg}$ $\left(r^{2}=0.11\right)$ and AUC $\left(r^{2}=0.15\right)$ followed by age (Table 2).

When HIV status was added into a combined regression model, a clear status effect was demonstrated, with HIV infection being the most important predictor of both low GH peak ( $\beta$-coefficient: 13.315, $P$ level $<0.0001)$ and AUC $(\beta$-coefficient: 1089.645 , $P$ level $<0.0001)$.

\section{Discussion}

To our knowledge, this is the largest study of HIVinfected women investigating $\mathrm{GH}$ secretion in comparison with healthy matched controls. This study establishes that i) $\mathrm{GH}$ response to $\mathrm{GHRH}+\mathrm{Arg}$ is lower in HIV-infected women with lipoatrophy than in healthy matched controls, ii) GH peak after GHRH+Arg is impaired in $\sim 20 \%$ of HIV-infected women with lipoatrophy depending on the cutoff used, iii) BMI more than VAT or trunk fat influences GH peak among lipoatrophic HIV-infected women, and iv) HIV-infected women with a $\mathrm{GH}$ peak $\leq 7.5 \mu \mathrm{g} / \mathrm{l}$ demonstrate reduced serum IGF1, IGFBP3, BMD, and quality of life and may thus be considered relatively $\mathrm{GH}$ deficient.

In this large sample of subjects, both the $\mathrm{GH}$ peak and the AUC after GHRH + Arg were significantly lower in HIV-infected women with lipoatrophy than in healthy controls, thus demonstrating that pituitary GH reserve may be impaired in HIV-infected women, as previously suggested in men $(6,7,8,9)$. Different from previous studies $(7,8)$, GH secretion was significantly different in HIV-infected women compared with controls. Even though it is difficult to compare results coming from different settings, the $\mathrm{GH}$ peak in these HIV-infected women seems to be lower, on average, with respect to that obtained by Koutkia et al. (7). The percentage of postmenopausal women is similar in HIV-infected patients and controls and serum estradiol levels did not influence GH peak and AUC (Supplementary Tables 1 and 2).
However, as HIV-infected patients are mainly lipoatrophic, in this study they represent a different patient population from females of approximately the same age in previous studies (7) and caution is therefore needed in drawing conclusions when comparing different studies due to the GH assay variability $(13,14)$ and other factors, such as ethnicity (29), which could lead to different results. Since GHRH + Arg only tests pituitary reserve, this methodological approach does not allow us to obtain information about hypothalamic functioning in the current study.

In this paper, a significant percentage of HIV-infected women with lipoatrophy had an impaired $\mathrm{GH}$ peak after GHRH + Arg according to the various cutoffs used for both general $(15,16)$ and/or overweight-obese populations (18). The percentage of HIV-infected patients failing to respond to $\mathrm{GHRH}+$ Arg varied from 28.2 to $20.6 \%$, and $8.7 \%$ when the cutoffs of $9.0,7.5$, and $4.2 \mu \mathrm{g} / \mathrm{l}$ respectively were considered (Fig. 1). Although relatively modest, these percentages are of significance when compared with those obtained in healthy controls $(15,18)$ or epidemiological data on the prevalence of $\mathrm{GHD}$ in adults $(30,31,32)$. At present, the most appropriate cutoffs to define deficient $\mathrm{GH}$ secretory response to GHRH+Arg in the context of HIV remain unknown.

The strength of this study lies in the direct measurement of fat tissue distribution by DXA in both patients and controls. DXA, even though less accurate than CT scan, is a valid tool for estimating truncal adiposity, being a valid surrogate and strongly representative of VAT (26). In the univariate analyses (Supplementary Table 1), GH response to GHRH+ Arg, in terms of GH peak and AUC, was related to truncal fat in HIV-infected and -uninfected subjects, but this association was not seen in the multivariate analysis. When considering CT scan parameters, GH peak and AUC were inversely related to VAT in univariate analysis but not in multivariate regression analysis among the HIV-infected patients in whom VAT was assessed by CT (Supplementary Table 1).

Taken together, our findings suggest that HIV status was the strongest predictor of both low GH peak and AUC among all the subjects. Visceral adiposity was inversely related to $\mathrm{GH}$ response to $\mathrm{GHRH}+\mathrm{Arg}$, but its effect was less than expected and is less than that exerted by BMI. Possible explanations for the stronger influence of BMI than VAT on GH peak and AUC, in this study, could be that HIV-infected patients were primarily lipoatrophic and obese subjects were excluded. Taken together, these findings suggest that factors in addition to excess visceral adiposity help to explain reduced GH secretion in HIV-infected women. Among them, the HIV itself, HAART treatments, the poor general health in these patients, their chronic inflammation, and alterations in immune system are all factors that need to be further investigated since they may act centrally on the hypothalamic-pituitary unit to modify pituitary 
Table 2 (A) Stepwise regression models estimating predictive factors for GH peak response to GHRH+Arg in the HIV-infected patients by considering as independent variables adiposity measured by both dual-energy X-ray absorptiometry (DXA) or abdominal CT scan. (B) Stepwise regression models estimating predictive factors for AUC of the GH response to GHRH+Arg in the HIV-infected patients by considering as independent variables adiposity measured by both DXA or abdominal CT scan.

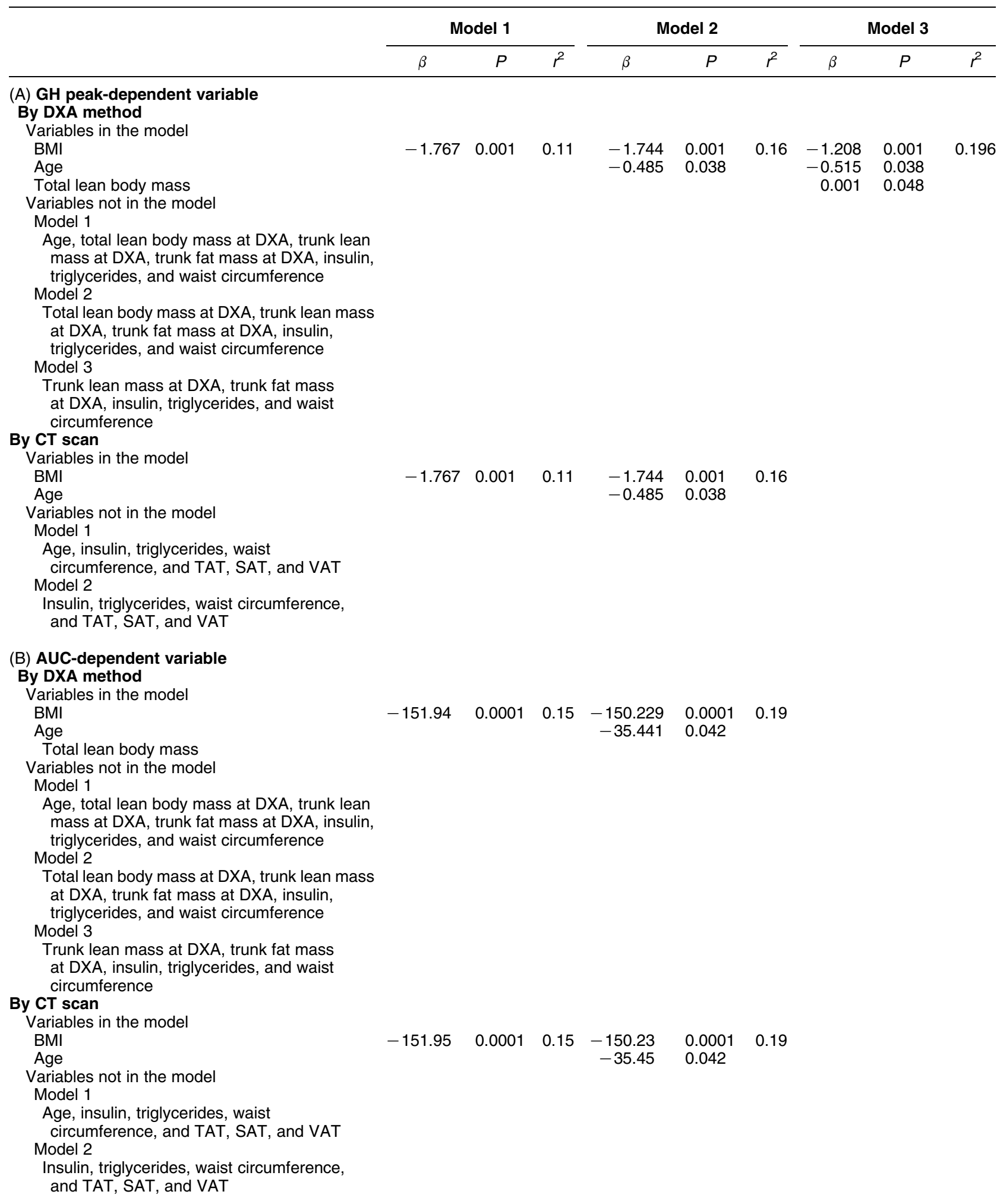

$\beta$, Coefficient of regression; SE, standard error of $\beta ; t$, $t$ value of $\beta$. Sig., significance of two-tailed test. 
hormonal secretion (19). Recently, we demonstrated a high rate of secondary hypogonadism (low testosterone and low to normal LH) in a large cohort of HIV-infected men (33), suggesting that the function of the hypothalamic-pituitary unit could be impaired in HIV infection. Since the design of this study was not specifically addressed at identifying the underlying mechanisms involved in the impaired GH secretion, we may only speculate on possible hypothalamicpituitary dysfunction in HIV infection.

In addition to reduced serum levels of IGF1 and IGFBP3, HIV-infected females with peak GH $\leq 7.5 \mu \mathrm{g} / \mathrm{l}$ showed reduced quality of life and impaired bone health in comparison with HIV-infected patients with a normal GH peak (Supplementary Table 3). These findings support the idea that HIV-infected females with impaired GH peak demonstrate some of the features of GHD associated with traditional hypopituitarism (34, 35). Although unlikely, we cannot exclude hypothalamic-pituitary diseases because the morphology of this area was not studied by MRI. In the absence of confirmed abnormalities of the hypothalamic-pituitary unit, a diagnosis of true GHD could not be confirmed in these HIV-infected individuals because provocative testing with GHRH+Arg must be put into the appropriate clinical context of a known pituitary or hypothalamic process $(13,14,35)$.

Whether HIV-infected females with reduced GH could benefit from $\mathrm{r}$-hGH replacement treatment remains unknown. At present, $\mathrm{r}$-hGH treatment is not indicated in HIV infection $(13,14)$, except for the treatment of AIDS- and HIV-related muscle wasting in the USA (36). Thus, treating HIV-infected individuals with documented biochemical evidence of GHD should be considered off-label and inappropriate. However, recent studies suggest beneficial effects of a GHRH analog among HIV-infected patients with central fat accumulation, and this benefit on visceral fat was seen specifically in subanalyses performed among HIV-infected women enrolled in the studies $(37,38,39)$.

Future studies are needed to further investigate the effects of GH and GHRH analog on body composition, BMD, and quality of life among HIV-infected women and especially among women with impairment of the GH axis. Whether biochemical GHD should be considered as a true clinical GHD in HIV-infected females and should be treated remains unsolved. Probably, reduced GH secretory response observed in this study is functional, but the differences between HIV patients with and without peak GH response in terms of the quality of life and BMD speak in favor of the presence of clinical conditions similar to those of patients who suffer from true GHD in these patients with HIV. Hence, it is possible that a subset of HIV-infected patients with significant reductions in GH secretory response may benefit from augmentation of the $\mathrm{GH}$ axis as an endpoint, to improve quality of life and BMD, in addition to VAT. As a word of caution, recent data suggest that adiposity in
HIV-infected patients with GHD was worsened after the withdrawal of physiological doses of r-hGH (40), perhaps due to prolonged suppression of the GH axis from exogenous GH. In distinction, this effect was not seen with GHRH analog, which does not suppress pituitary function. Our results may be of help in identifying patients who may benefit from augmentation of the GH axis.

This study not only has some strengths, such as the great number of participants and the lack of obese women enrolled, but also has several limitations that are listed below. As estrogens may positively modulate $\mathrm{GH}$ secretion, the first limitation is that the subjects enrolled in the study were tested for GH secretion irrespective of their phase of the menstrual cycle and the sample we studied also included postmenopausal women. The lack of FFA measurement represents the second main limitation of this study, as FFAs decrease GH secretion and impair GH response to secretagogue in both HIV-infected patients (9) and HIV-uninfected subjects (41). Thirdly, GHRH + Arg assesses the integrity of the GH pituitary reserve, thus in this setting the hypothalamic function could not be tested. Fourthly, CT scan was not performed in controls, thus limiting the chance to compare VAT among HIVinfected and -uninfected subjects. Finally, the lack of information on the morphology of the hypothalamicpituitary area does not allow us to determine whether some of the HIV-infected women with an impaired GH peak suffered from other diseases causing GHD.

In conclusion, our data suggest reduced GH peak and AUC after GHRH + Arg testing in HIV compared with matched controls and suggests a lesser role of VAT in influencing GH response to GHRH + Arg among HIVinfected lipoatrophic, nonobese women. Furthermore, this study suggests that $\sim 20 \%$ of HIV-infected females with lipoatrophy fail to respond to GHRH + Arg using previously reported cutoffs and these patients exhibit low BMD and poor quality of life typical of true GHD, although our data do not permit us to formally establish this diagnosis in our subjects. Similarly, the optimal cutoff for the diagnosis of reduced GH secretory response in HIV infection remains uncertain, even though using more restrictive cutoffs may result in less misclassification. As changes in body composition typical of HIV-infected women with lipodystrophy do not fully explain reduced GH secretory response in the patients studied and a primary hypothalamic-pituitary disease causing true GHD in such a large percentage is unlikely, our data suggest that other factors including the HIV virus, HAART treatment, and health status might affect hypothalamic-pituitary function in HIV and should be further investigated. This study provides new information on GH status in HIV-infected women. Further studies are needed to investigate the potential utility and optimal targeting of r-hGH and GHRH analog in HIV-infected women. 


\section{Supplementary data}

This is linked to the online version of the paper at http://dx.doi.org/10. 1530/EJE-11-0829.

\section{Declaration of interest}

The authors declare that there is no conflict of interest that could be perceived as prejudicing the impartiality of the research reported.

\section{Funding}

This work is based on an independent study protocol, supported by an independent grant from Ely Lilly, Italia, and sponsored by Ministero dell'Università e della Ricerca (MUR, ex-40\%-2005). Ely Lilly Company had no role in the conception/design of the study, in the acquisition, elaboration and interpretation of data, in drafting/ revising the manuscript, or in the decision to submit the paper for publication.

\section{Acknowledgements}

We are indebted to Ely Lilly Italia for having cosupported the study and to Enrica Baraldi and Maria Cristina De Santis, Laboratory of Endocrinology, AUSL of Modena for technical support in hormonal assays. We are grateful to Giuseppina Rossi (Department of Medicine, Endocrinology and Metabolism, and Geriatrics, Chair of Endocrinology, University of Modena and Reggio Emilia) for editing the manuscript. We thank all the healthy control women who participated in the study. We thank Dr Yael Ukmar for proofreading the manuscript and Erica Taliani MD, Daniele Santi, and Giulia Brigante MD for their help in clinical and radiological assessment of healthy control females.

\section{References}

1 Samaras K. Endocrine disease in HIV infection. Best Practice and Research. Clinical Endocrinology and Metabolism 201125 vii-viii. (doi:10.1016/j.beem.2011.04.006)

2 Brown TT. The effects of HIV-1 infection on endocrine organs. Best Practice and Research. Clinical Endocrinology and Metabolism 2011 25 403-413. (doi:10.1016/j.beem.2011.04.005)

3 Stanley TL \& Grinspoon SK. GH/GHRH axis in HIV lipodystrophy. Pituitary 200912 143-152. (doi:10.1007/s11102-008-0092-8)

4 Falutz J. Growth hormone and HIV infection: contribution to disease manifestations and clinical implications. Best Practice and Research. Clinical Endocrinology and Metabolism 201125 517-529. (doi:10.1016/j.beem.2010.11.001)

5 Brown TT. Approach to the human immunodeficiency virusinfected patient with lipodystrophy. Journal of Clinical Endocrinology and Metabolism 200893 2937-2945. (doi:10.1210/jc.20081019)

6 Koutkia P, Canavan B, Breu J \& Grinspoon S. Growth hormone (GH) responses to GH-releasing hormone-arginine testing in human immunodeficiency virus lipodystrophy. Journal of Clinical Endocrinology and Metabolism 200590 32-38. (doi:10.1210/jc. 2004-1342)

7 Koutkia P, Eaton K, You SM, Breu J \& Grinspoon S. Growth hormone secretion among HIV infected patients: effects of gender, race and fat distribution. AIDS 200620 855-862. (doi:10.1097/ 01.aids.0000218549.85081.8f)

8 Lo J, You SM, Wei J, Canavan B \& Grinspoon S. Relationship of peak growth hormone to cardiovascular parameters, waist circumference, lipids and glucose in HIV-infected patients and healthy adults. Clinical Endocrinology 200971 815-822. (doi:10.1111/j. 1365-2265.2009.03603.x)
9 Koutkia P, Meininger G, Canavan B, Breu J \& Grinspoon S. Metabolic regulation of growth hormone by free fatty acids, somatostatin, and ghrelin in HIV-lipodystrophy. American Journal of Physiology. Endocrinology and Metabolism 2004286 E296-E303. (doi:10.1152/ajpendo.00335.2003)

10 Veldhuis JD, Erickson D, Mielke K, Farhy LS, Keenan DM \& Bowers CY. Distinctive inhibitory mechanisms of age and relative visceral adiposity on growth hormone secretion in pre- and postmenopausal women studied under a hypogonadal clamp. Journal of Clinical Endocrinology and Metabolism $2005906006-$ 6013. (doi:10.1210/jc.2005-0854)

11 Weltman A, Weltman JY, Hartman ML, Abbott RD, Rogol AD, Evans WS \& Veldhuis JD. Relationship between age, percentage body fat, fitness, and 24-hour growth hormone release in healthy young adults: effects of gender. Journal of Clinical Endocrinology and Metabolism 199478 543-548. (doi:10.1210/jc.78.3.543)

12 Vahl N, Jørgensen JO, Skjærbæk C, Veldhuis JD, Ørskow H \& Christiansen JS. Abdominal adiposity rather than age and sex predicts mass and regularity of $\mathrm{GH}$ secretion in healthy adults. American Journal of Physiology 1997272 E1108-E1116.

13 Ho KK. GH Deficiency Consensus Workshop Participants. Consensus guidelines for the diagnosis and treatment of adults with GH deficiency II: a statement of the GH Research Society in association with the European Society for Pediatric Endocrinology, Lawson Wilkins Society, European Society of Endocrinology, Japan Endocrine Society, and Endocrine Society of Australia. European Journal of Endocrinology 2007157 695-700. (doi:10.1530/EJE07-0631)

14 Molitch ME, Clemmons DR, Malozowski S, Merriam GR \& Vance ML \& Endocrine Society. Evaluation and treatment of adult growth hormone deficiency: an Endocrine Society clinical practice guideline. Journal of Clinical Endocrinology and Metabolism 201196 1587-1609. (doi:10.1210/jc.2011-0179)

15 Aimaretti G, Corneli G, Razzore P, Bellone S, Baffoni C, Arvat E, Camanni $\mathrm{F} \&$ Ghigo E. Comparison between insulin-induced hypoglycemia and growth hormone $(\mathrm{GH})$-releasing hormone plus arginine as provocative tests for the diagnosis of GH deficiency in adults. Journal of Clinical Endocrinology and Metabolism $1998 \mathbf{8 3}$ 1615-1618. (doi:10.1210/jc.83.5.1615)

16 Aimaretti G, Corneli G, Di Somma C, Baldelli R, Gasco V, Rovere S, Migliaretti G, Colao A, Tamburrano G, Lombardi G, Ghigo E \& Camanni F. Different degrees of GH deficiency evidenced by GHRH + arginine test and IGF-I levels in adults with pituitary disease. Journal of Endocrinological Investigation 200528 247-252.

17 Cordido F, Alvarez-Castro P, Isidro ML, Casanueva FF \& Dieguez C. Comparison between insulin tolerance test, growth hormone (GH)-releasing hormone (GHRH), GHRH plus acipimox and GHRH plus GH-releasing peptide- 6 for the diagnosis of adult $\mathrm{GH}$ deficiency in normal subjects, obese and hypopituitary patients. European Journal of Endocrinology 2003149 117-122. (doi:10. 1530/eje.0.1490117)

18 Corneli G, Di Somma C, Baldelli R, Rovere S, Gasco V, Croce CG, Grottoli S, Maccario M, Colao A, Lombardi G, Ghigo E, Camanni F \& Aimaretti G. The cut-off limits of the $\mathrm{GH}$ response to GH-releasing hormone-arginine test related to body mass index. European Journal of Endocrinology 2005153 257-264. (doi:10. 1530/eje.1.01967)

19 Zirilli L, Orlando G, Diazzi C, Squillace N, Carani C, Guaraldi G \& Rochira V. Hypopituitarism and HIV-infection: a new comorbidity in the HAART era? Journal of Endocrinological Investigation 200831 33-38.

20 Falutz J, Allas S, Kotler D, Thompson M, Koutkia P, Albu J, Trottier B, Routy JP, Cote P, Abribat T \& Grinspoon S. A placebocontrolled, dose-ranging study of a growth hormone releasing factor in HIV-infected patients with abdominal fat accumulation. AIDS 200519 1279-1287. (doi:10.1097/01.aids.0000180099. 35146.30)

21 Rietschel P, Hadigan C, Corcoran C, Stanley T, Neubauer G, Gertner J \& Grinspoon S. Assessment of growth hormone 
dynamics in human immunodeficiency virus-related lipodystrophy. Journal of Clinical Endocrinology and Metabolism $2001 \mathbf{8 6}$ 504-510. (doi:10.1210/jc.86.2.504)

22 Fiorenza CG, Chou SH \& Mantzoros CS. Lipodystrophy: pathophysiology and advances in treatment. Nature Reviews. Endocrinology 20117 137-150. (doi:10.1038/nrendo.2010.199)

23 Leung VL \& Glesby MJ. Pathogenesis and treatment of HIV lipohypertrophy. Current Opinion in Infectious Diseases 201124 43-49. (doi:10.1097/QCO.0b013e3283420eef)

24 Lichtenstein KA, Ward DJ, Moorman AC, Delaney KM, Young B, Palella FJ Jr, Rhodes PH, Wood KC \& Holmberg SD \& HIV Outpatient Study Investigators. Clinical assessment of HIVassociated lipodystrophy in an ambulatory population. AIDS 200115 1389-1398. (doi:10.1097/00002030-20010727000008)

25 Park YW, Heymsfield SB \& Gallagher D. Are dual-energy X-ray absorptiometry regional estimates associated with visceral adipose tissue mass? International Journal of Obesity and Related Metabolic Disorders 200226 978-983. (doi:10.1038/sj.ijo.0801982)

26 Clasey JL, Bouchard C, Teates CD, Riblett JE, Thorner MO, Hartman ML \& Weltman A. The use of anthropometric and dual-energy X-ray absorptiometry (DXA) measures to estimate total abdominal and abdominal visceral fat in men and women. Obesity Research 19997 256-264.

27 Borkan GA, Gerzof SG, Robbins AH, Hults DE, Silbert CK \& Silbert JE. Assessment of abdominal fat content by computed tomography. American Journal of Clinical Nutrition 198236 172-177.

28 Webb SM. Measurements of quality of life in patients with growth hormone deficiency. Journal of Endocrinological Investigation 2008 $3152-55$.

29 Healy ML, Dall R, Gibney J, Bassett E, Ehrnborg C, Pentecost C, Rosen T, Cittadini A, Baxter RC \& Sönksen PH. Toward the development of a test for growth hormone (GH) abuse: a study of extreme physiological ranges of GH-dependent markers in 813 elite athletes in the postcompetition setting. Journal of Clinical Endocrinology and Metabolism 200590 641-649. (doi:10.1210/ jc.2004-0386)

30 Goth MI, Hubina E \& Korbonits M. Aetiology and demography of adult growth hormone deficiency. In Growth Hormone Deficiency in Adults: 10 Years of KIMS, ch 7, pp 75-82. Eds R Abs \& U FeldtRasmussen. Oxford: Oxford PharmaGenesis, 2004.

31 Erfurth EM. Epidemiology of adult growth hormone deficiency. Prevalence, incidence, mortality and morbidity. Frontiers of Hormone Research 200533 21-32. (doi:10.1159/000088397)

32 Stochholm K, Gravholt CH, Laursen T, Jørgensen JO, Laurberg P, Andersen M, Kristensen LØ, Feldt-Rasmussen U, Christiansen JS, Frydenberg M \& Green A. Incidence of GH deficiency - a nationwide study. European Journal of Endocrinology $2006 \mathbf{1 5 5}$ 61-71. (doi:10.1530/eje.1.02191)
33 Murray RD, Bidlingmaier M, Strasburger CJ \& Shalet SM. The diagnosis of partial growth hormone deficiency in adults with a putative insult to the hypothalamo-pituitary axis. Journal of Clinical Endocrinology and Metabolism 200792 1705-1709. (doi:10.1210/jc.2006-2055)

34 Prodam F, Pagano L, Corneli G, Golisano G, Belcastro S, Busti A, Gasco V, Beccuti G, Grottoli S, Di Somma C, Colao A, Ghigo E \& Aimaretti G. Update on epidemiology, etiology, and diagnosis of adult growth hormone deficiency. Journal of Endocrinological Investigation 200831 6-11.

35 Rochira V, Zirilli L, Orlando G, Santi D, Brigante G, Diazzi C, Carli F, Carani C \& Guaraldi G. Premature decline of serum total testosterone in HIV-infected men in the HAART-Era. PLOS ONE 20116 e28512. (doi:10.1371/journal.pone.0028512)

36 Melmed S. Supplemental growth hormone in healthy adults: the endocrinologist's responsibility. Nature Clinical Practice. Endocrinology and Metabolism 20062 119. (doi:10.1038/ ncpendmet0138)

37 Sivakumar T, Mechanic O, Fehmie D \& Paul B. Growth hormone axis treatments for HIV-associated lipodystrophy: a systematic review of placebo-controlled trials. HIV Medicine 201112 453-462. (doi:10.1111/j.1468-1293.2010.00906.x)

38 Falutz J, Allas S, Blot K, Potvin D, Kotler D, Somero M, Berger D, Brown S, Richmond G, Fessel J, Turner R \& Grinspoon S. Metabolic effects of a growth hormone-releasing factor in patients with HIV. New England Journal of Medicine 2007357 2359-2370. (doi:10. 1056/NEJMoa072375)

39 Falutz J, Mamputu JC, Potvin D, Moyle G, Soulban G, Loughrey H, Marsolais C, Turner R \& Grinspoon S. Effects of tesamorelin (TH9507), a growth hormone-releasing factor analog, in human immunodeficiency virus-infected patients with excess abdominal fat: a pooled analysis of two multicenter, double-blind placebocontrolled phase 3 trials with safety extension data. Journal of Clinical Endocrinology and Metabolism 201095 4291-4304. (doi:10.1210/jc.2010-0490)

40 Lo J, You SM, Liebau J, Lee H \& Grinspoon S. Effects of low-dose growth hormone withdrawal in patients with HIV. Journal of the American Medical Association 2010304 272-274. (doi:10.1001/ jama.2010.989)

41 Maccario M, Procopio M, Grottoli S, Oleandri SE, Boffano GM, Taliano M, Camanni F \& Ghigo E. Effects of acipimox, an antilipolytic drug, on the growth hormone $(\mathrm{GH})$ response to $\mathrm{GH}-$ releasing hormone alone or combined with arginine in obesity. Metabolism 199645 342-346. (doi:10.1016/S0026-0495(96) 90288-7)

Received 22 September 2011

Revised version received 29 November 2011

Accepted 20 December 2011 